\title{
Early growth and postprandial appetite regulatory hormone responses
}

\author{
Mia-Maria Perälä ${ }^{1 *}$, Eero Kajantie ${ }^{1,2}$, Liisa M. Valsta ${ }^{3,4}$, Jens J. Holst ${ }^{5}$, Jaana Leiviskä ${ }^{1}$ and \\ Johan G. Eriksson ${ }^{1,6,7,8,9}$ \\ ${ }^{1}$ Department of Chronic Disease Prevention, The National Institute for Health and Welfare, Helsinki, Finland \\ ${ }^{2}$ Hospital for Children and Adolescents, Helsinki University Central Hospital, University of Helsinki, Helsinki, Finland \\ ${ }^{3}$ Department of Lifestyle and Participation, The National Institute for Health and Welfare, Helsinki, Finland \\ ${ }^{4}$ European Food and Safety Authority, Data Collection and Exposure, Parma, Italy \\ ${ }^{5}$ Department of Biomedical Sciences, NNF Center for Basic Metabolic Research, University of Copenhagen, Denmark \\ ${ }^{6}$ Department of General Practice and Primary Health Care, University of Helsinki, Helsinki, Finland \\ ${ }^{7}$ Unit of General Practice, Helsinki University Central Hospital, Helsinki, Finland \\ ${ }^{8}$ Folkhälsan Research Center, Helsinki, Finland \\ ${ }^{9}$ Vaasa Central Hospital, Vaasa, Finland \\ (Submitted 18 September 2012 - Final revision received 22 February 2013 - Accepted 22 February 2013 - First published online 19 April 2013)
}

\section{Abstract}

Strong epidemiological evidence suggests that slow prenatal or postnatal growth is associated with an increased risk of CVD and other metabolic diseases. However, little is known whether early growth affects postprandial metabolism and, especially, the appetite regulatory hormone system. Therefore, we investigated the impact of early growth on postprandial appetite regulatory hormone responses to two high-protein and two high-fat content meals. Healthy, 65-75-year-old volunteers from the Helsinki Birth Cohort Study were recruited; twelve with a slow increase in BMI during the first year of life (SGI group) and twelve controls. Subjects ate a test meal (whey meal, casein meal, SFA meal and PUFA meal) once in a random order. Plasma glucose, insulin, TAG, NEFA, ghrelin, peptide tyrosine-tyrosine (PYY), glucose-dependent insulinotropic peptide, glucagon-like peptide-1 and a satiety profile were measured in the fasting state and for $4 \mathrm{~h}$ after each test meal. Compared with the controls, the SGI group had about 1.5-fold higher insulin responses after the whey meal $(P=0.037)$, casein meal $(P=0.023)$ and PUFA meal $(P=0.002)$. TAG responses were $34-69 \%$ higher for the SGI group, but only the PUFA-meal responses differed significantly between the groups. The PYY response of the SGI group was $44 \%$ higher after the whey meal $(P=0.046)$ and $115 \%$ higher after the casein meal $(P=0.025)$ compared with the controls. No other statistically significant differences were seen between the groups. In conclusion, early growth may have a role in programming appetite regulatory hormone secretion in later life. Slow early growth is also associated with higher postprandial insulin and TAG responses but not with incretin levels.

\section{Key words: Postprandial responses: Early growth: Birth weight: Appetite: Incretin}

Epidemiological studies have shown that low birth weight and slow growth during infancy predict an increased risk of metabolic diseases including $\mathrm{CVD}^{(1)}$ and type 2 diabetes $^{(2)}$ in later life. Although obesity is closely linked with these disorders, large body size at birth and rapid growth during the early postnatal period are primarily related to obesity ${ }^{(3-6)}$.

It has been suggested that prenatal growth as well as growth during early infancy may influence the appetite regulatory system by programming appetite regulatory hormones, such as an orexigenic (ghrelin) and an anorexigenic (peptide tyrosine-tyrosine; PYY). Animal studies have supported this hypothesis, showing that postnatal growth retardation has an effect on appetite regulation ${ }^{(7-9)}$ and that the prevention of immediate rapid newborn catch-up growth may reduce the risk of obesity ${ }^{(10,11)}$. In addition, an epidemiological study of young adolescents has found an association between rapid early growth and the elevated fasting concentration of ghrelin ${ }^{(12)}$. Furthermore, increased PYY and decreased ghrelin concentrations have been described in young children who were born with low birth weight ${ }^{(13)}$. However, not all studies have supported the findings of decreased ghrelin levels in subjects born small-for-gestational age ${ }^{(14-17)}$.

Recently, we have investigated the acute effects of early growth on postprandial responses after a fast-food meal and

Abbreviations: CON group, control group; GIP, glucose-dependent insulinotropic peptide; GLP-1, glucagon-like peptide-1; PYY, peptide tyrosine-tyrosine; SGI group, slow growth during infancy.

*Corresponding author: M.-M. Perälä, fax +358 29524 8661, email mia.perala@thl.fi 
a meal whose macronutrient content was according to dietary guidelines. We found that participants who had grown slowly during early life had elevated postprandial insulin and TAG levels compared with the controls; however no changes in glucose levels were observed ${ }^{(18)}$. In addition, although TAG responses were significantly greater for participants with slow growth during early life, postprandial inflammatory responses of IL- 6 , TNF- $\alpha$ and monocyte chemoattractant protein-1 were similar in both groups ${ }^{(19)}$. To our knowledge, no study has investigated the effect of postnatal growth on postprandial appetite regulatory hormone levels in adulthood.

The incretins glucose-dependent insulinotropic peptide (GIP) and glucagon-like peptide-1 (GLP-1) are released from enteroendocrine cells in the proximal and distal gut. They directly stimulate pancreatic $\beta$-cells in response to the ingestion of meals or glucose, and this so-called incretin effect accounts for approximately $50-70 \%$ of the total insulin secretion after a meal ${ }^{(20)}$. Alterations in incretin secretion have been shown in type 2 diabetics ${ }^{(20,21)}$. Although it is widely known that early growth affects glucose and insulin metabolism, it is still unknown whether alterations in incretin secretion explain in part the abnormal insulin secretion among individuals born small-for-gestational age or who grew slowly during infancy. As far as we are aware, only one study has investigated birth weight and postprandial incretin levels and detected similar incretin responses between lean, young adults born with a low birth weight and age- and BMI-matched controls ${ }^{(22)}$.

The primary aim of the present study was to examine the effect of early growth on appetite regulatory hormone responses to two high-fat content and two high-protein content meals. The same participants' postprandial glucose, insulin, lipids and inflammatory responses after a fast-food meal and a meal whose macronutrient content was according to dietary guidelines have been reported earlier ${ }^{(18,19)}$. High-fat and high-protein content meals were chosen because protein and fat induce the secretion of the appetite regulatory hormones PYY and GLP-1 and suppress the secretion of ghrelin. Furthermore, the secondary aim was to study whether early growth affects incretin secretion and glucose, insulin and lipid responses in adult life.

\section{Experimental methods}

\section{Participants}

We studied twenty-four overweight (BMI $25-32 \mathrm{~kg} / \mathrm{m}^{2}$ ), 65-75-year-old subjects, twelve with slow growth during infancy (SGI group) and twelve sex-, age- and current BMImatched controls (CON group), from the Helsinki Birth Cohort Study ${ }^{(23)}$. All individuals (except one) had recently participated in a study in which their postprandial responses after a fast-food meal and a healthy meal were investigated ${ }^{(18)}$. Data on childhood growth were based on repeated measurements at child welfare clinics, which have been described previously in detail ${ }^{(23)}$. Growth during infancy was examined as gains in BMI between birth and 1 year. We converted each measurement of BMI for each individual to a $Z$-score, which represents the difference from the mean value for the whole birth cohort ( $n$ 2003) and is expressed as standard deviations. We examined how much BMI at 1 year of age differed from that predicted by BMI at birth by using the residual from linear regression; this measure was called 'conditional growth'. Subjects in the SGI group had a conditional growth $<-0.9 \mathrm{SD}$, and the conditional growth of the CON group was $>-0.9 \mathrm{sD}$. We excluded those who were born preterm (before 37 weeks of gestation).

Glucose tolerance was assessed by a $75 \mathrm{~g}, 2 \mathrm{~h}$ oral glucose tolerance test, and diabetics were excluded. Other exclusion criteria were smoking, milk allergy, regular medication that would have an effect on postprandial glucose or lipid metabolism (e.g. antidiabetic drugs, fibrates, glucocorticoids), gastrointestinal disease influencing absorption or a firstdegree family history of diabetes. Blood donation $<90 \mathrm{~d}$ before the study was not permitted. Diet, health and lifestyle data were assessed by questionnaires.

The present study was conducted according to the guidelines laid down in the Declaration of Helsinki, and all procedures involving human subjects were approved by the Ethics Committee of the Hospital District of Helsinki and Uusimaa. Written informed consent was obtained from all the subjects.

\section{Study design}

The study followed a cross-over design. Subjects were recruited to participate in a random order in four $1 \mathrm{~d}$ studies, separated by approximately 1 week. The participants were requested to maintain their habitual diet and exercise routines throughout the study period. In addition, they were not allowed to drink alcohol, and were asked to avoid strenuous exercise and sauna for $24 \mathrm{~h}$ before each study day. Moreover, subjects were advised not to take lipid-lowering medication (statins) preceding the study day. The day before the study visit, they were asked to eat an evening meal, in accordance with the instructions they had been given, which would provide $15 \%$ of the calculated daily energy requirement. The carbohydrate content of the evening meal was $55 \%$ of total energy intake (percentage of energy). The subjects' mean energy intake was calculated on the basis of their calculated BMR, taking into account the questionnaire data on daily physical activity ${ }^{(24)}$. Subjects were also asked to fast for $10-12 \mathrm{~h}$ after their standardised evening meal, to avoid exercise on the morning of the study, and to arrive at the clinic by car or public transportation.

In the study clinic, body weight and height were measured and BMI was calculated (changes $\leq 2 \mathrm{~kg}$ in weight were allowed throughout the whole study period). An intravenous cannula was inserted into an antecubital vein in the forearm and an intravenous blood sample $(8 \mathrm{ml})$ was drawn. Thereafter, subjects consumed the test meal within $10 \mathrm{~min}$. After the start of the meal, venous blood samples were collected at $15,30,60,90,120,180$ and $240 \mathrm{~min}$.

All participants consumed four different test meals. The foodstuffs and the nutrient composition of the test meals are shown in Table 1. Of the four test meals, two high-protein 
Table 1. Foodstuffs and nutrient content of the test meals

\begin{tabular}{|c|c|c|c|c|}
\hline & $\begin{array}{l}\text { Whey meal } \\
\text { (g/portion) }\end{array}$ & $\begin{array}{c}\text { Casein meal } \\
\text { (g/portion) }\end{array}$ & $\begin{array}{l}\text { PUFA meal } \\
\text { (g/portion) }\end{array}$ & $\begin{array}{l}\text { SFA meal } \\
\text { (g/portion) }\end{array}$ \\
\hline \multicolumn{5}{|l|}{ Components } \\
\hline White bread* & 37 & 37 & - & - \\
\hline Rye bread $\dagger$ & - & - & 45 & 45 \\
\hline Margarine $70 \% \ddagger$ & - & - & 11 & - \\
\hline Butter§ & 25 & 25 & - & 60 \\
\hline Liquid rapeseed oil margarine\| & - & - & 51 & - \\
\hline Cucumber & 40 & 40 & 40 & 40 \\
\hline Water & 400 & 400 & 350 & 350 \\
\hline Milk powderף & - & - & 23 & 23 \\
\hline Cocoa powder ${ }^{* *}$ & 27 & 27 & 26 & 26 \\
\hline Wheyt† & 44 & - & - & - \\
\hline Casein§§ & - & 44 & - & - \\
\hline Vanilla sugar & 5 & 5 & - & - \\
\hline Sugar & 15 & 15 & - & - \\
\hline \multicolumn{5}{|l|}{ Carbohydrate } \\
\hline g & 59 & 59 & 51 & 51 \\
\hline $\mathrm{E} \%$ & 38 & 38 & 29 & 29 \\
\hline \multicolumn{5}{|l|}{ Protein } \\
\hline $\mathrm{g}$ & 45 & 45 & 12 & 12 \\
\hline E\% & 29 & 29 & 7 & 7 \\
\hline \multicolumn{5}{|l|}{ Fat } \\
\hline g & 23 & 23 & 50 & 50 \\
\hline E\% & 33 & 33 & 64 & 64 \\
\hline Energy (kJ) & 2638 & 2638 & 2961 & 2961 \\
\hline
\end{tabular}

$\mathrm{E} \%$, percentage of energy.

* White bread (Vaasan Iso Paahto - vehnä; Vaasan \& Vaasan Limited).

† Whole-grain rye bread (REAL-ruisleipä; Fazer Limited).

$\ddagger$ Keiju margarine $70 \%$ (Raisio Limited).

$\S$ Butter, lactose-free (Arla Limited).

|| Liquid margarine (Keiju Juokseva Rypsiöljyvalmiste; Raisio Limited).

ๆ Milk powder (fat-free, lactose-free) (Valio Limited).

** Dumle Cocoa powder (Fazer Limited).

†† Whey protein isolate (protein content $89 \mathrm{~g} / 100 \mathrm{~g}$ ) (Glanbia Nutritionals)

$\S \S$ Calcium caseinate I (protein content $90 \mathrm{~g} / 100 \mathrm{~g}$ ) (DMW International).

meals contained the same amount of energy (2638 kJ), carbohydrates $(59 \mathrm{~g}$ ), protein $(45 \mathrm{~g})$ and fat $(23 \mathrm{~g})$. Only the type of milk protein differed between the meals: whey protein isolate (whey meal) or calcium caseinate (casein meal). Also, two high-fat meals contained the same amount of energy $(2961 \mathrm{~kJ})$, carbohydrates $(51 \mathrm{~g})$, protein $(12 \mathrm{~g})$ and fat $(50 \mathrm{~g})$. Only the type of fat (saturated (SFA meal) or unsaturated (PUFA meal) fat) differed between the test meals.

\section{Appetite measurements}

Subjective satiety profiles were measured using a seven-point visual analogue scale ${ }^{(25)}$. Participants rated their satiety immediately before each blood sample was drawn. The categories were scored from 0 'I am extremely hungry' through 3 'No particular feeling' to 6 'I am extremely full'. Participants were requested to mark a vertical line on the horizontal axis corresponding to their sensations that were most appropriate at the time.

\section{Laboratory analysis}

Blood glucose was analysed by a glucose meter (HemoCue Glucose 201+ meter; HemoCue Limited), whose concentrations were expressed as $\mathrm{mmol} / \mathrm{l}$ plasma glucose. For the determination of plasma TAG, NEFA and insulin, blood was collected in EDTA K2 tubes (Venosafe TM; Terumo Sweden AB). For the determination of plasma PYY, ghrelin, GLP-1 and GIP, blood was collected in pre-chilled BD ${ }^{\mathrm{TM}}$ P800 tubes (Becton, Dickinson and Company), which contained dipeptidyl peptidase IV and other protease inhibitor cocktails. Immediately after the sample collection, the samples were centrifuged for $15 \mathrm{~min}$ at $4000 \mathrm{rpm}$ (Rotofix 32; Hettich Zentrifugen) and the separated plasma was stored at $-70^{\circ} \mathrm{C}$ until required for analysis. Plasma concentrations of TAG were measured by an enzymatic glycerol-3-phosphate oxidase method (Abbott Laboratories), NEFA were measured by an enzymatic colorimetric method (NEFA-HR(2); Wako Chemicals $\mathrm{GmbH}$ ) and insulin was determined by a chemiluminescent microparticle immunoassay with Abbott reagents. Fasting total cholesterol at baseline was analysed using an enzymatic method (Abbott Laboratories). Laboratory analyses of glucose, insulin, TAG and NEFA were carried out using the Architect ci8200 analyser (Abbott Laboratories). PYY (total), ghrelin (active) and GIP (total) were measured using the MILLIPLEX MAP Human Metabolic Hormone Panel kit (HMH-34K) using the Luminex 200 System (Luminex Corporation). Plasma concentrations of GLP-1 were measured against standards of synthetic GLP-1 7-36-amide using an antiserum (code no. $89390)^{(26)}$. The assay measures the sum of the intact, active 
Table 2. Baseline characteristics of the participants

(Mean values and standard deviations)

\begin{tabular}{|c|c|c|c|c|c|}
\hline & \multicolumn{2}{|c|}{ SGI group } & \multicolumn{2}{|c|}{ CON group } & \multirow[b]{2}{*}{$P^{*}$} \\
\hline & Mean & SD & Mean & SD & \\
\hline$n$ & \multicolumn{2}{|c|}{12} & \multicolumn{2}{|c|}{12} & \\
\hline Male & \multicolumn{2}{|c|}{6} & \multicolumn{2}{|c|}{6} & \\
\hline Female & \multicolumn{2}{|c|}{6} & \multicolumn{2}{|c|}{6} & \\
\hline \multicolumn{6}{|l|}{ Birth and childhood } \\
\hline Length of gestation (weeks) & 39.9 & $1 \cdot 3$ & $40 \cdot 3$ & 1.9 & 0.44 \\
\hline Birth weight $(\mathrm{g})$ & 3129 & 360 & 3597 & 469 & 0.012 \\
\hline Birth length $(\mathrm{cm})$ & $49 \cdot 6$ & $2 \cdot 4$ & $51 \cdot 0$ & 1.5 & 0.10 \\
\hline Birth BMI $\left(\mathrm{kg} / \mathrm{m}^{2}\right)$ & $12 \cdot 7$ & $1 \cdot 0$ & $13 \cdot 8$ & $1 \cdot 3$ & 0.032 \\
\hline BMI Z-score at birth & -0.66 & 0.85 & 0.26 & $1 \cdot 1$ & 0.032 \\
\hline Weight at 1 year $(\mathrm{kg})$ & 8.9 & 0.7 & $10 \cdot 8$ & 0.7 & $<0.001$ \\
\hline Height at 1 year $(\mathrm{cm})$ & $74 \cdot 7$ & $3 \cdot 1$ & $76 \cdot 9$ & 1.4 & 0.034 \\
\hline $\mathrm{BMI}$ at 1 year $\left(\mathrm{kg} / \mathrm{m}^{2}\right)$ & $15 \cdot 9$ & 0.5 & $18 \cdot 3$ & 0.8 & $<0.001$ \\
\hline BMI Z-score at 1 year & $-1 \cdot 34$ & 0.34 & 0.44 & 0.49 & $<0.001$ \\
\hline Conditional growth† & $-1 \cdot 23$ & 0.28 & 0.40 & 0.32 & $<0.001$ \\
\hline \multicolumn{6}{|l|}{ Adult } \\
\hline Age (years) & $68 \cdot 0$ & $2 \cdot 1$ & $68 \cdot 2$ & 3.4 & 0.89 \\
\hline Weight (kg) & 75.5 & 9.5 & 80.5 & $9 \cdot 8$ & 0.22 \\
\hline Height (cm) & $167 \cdot 1$ & $10 \cdot 0$ & $172 \cdot 9$ & $8 \cdot 6$ & 0.14 \\
\hline BMI $\left(\mathrm{kg} / \mathrm{m}^{2}\right)$ & $27 \cdot 0$ & $2 \cdot 8$ & $27 \cdot 0$ & $3 \cdot 1$ & 0.95 \\
\hline Waist circumference (cm) & $90 \cdot 1$ & $9 \cdot 7$ & $91 \cdot 6$ & $9 \cdot 8$ & 0.71 \\
\hline Fasting glucose $(\mathrm{mmol} / \mathrm{l}) \ddagger$ & 5.47 & 0.43 & $5 \cdot 54$ & 0.52 & 0.74 \\
\hline $2 \mathrm{~h}$ Glucose $(\mathrm{mmol} / \mathrm{l}) \S$ & 8.03 & 1.43 & $7 \cdot 77$ & 1.03 & 0.61 \\
\hline Fasting insulin $(\mathrm{pmol} / \mathrm{l}) \ddagger$ & $49 \cdot 7$ & $21 \cdot 2$ & $52 \cdot 4$ & $35 \cdot 6$ & 0.82 \\
\hline Fasting cholesterol $(\mathrm{mmol} / \mathrm{l}) \ddagger$ & $5 \cdot 06$ & 0.72 & $4 \cdot 72$ & 0.84 & 0.29 \\
\hline Fasting NEFA (mmol/l) $\ddagger$ & 0.44 & 0.19 & 0.52 & 0.12 & 0.20 \\
\hline Fasting TAG $(\mathrm{mmol} / \mathrm{l}) \ddagger$ & $1 \cdot 27$ & 0.43 & $1 \cdot 30$ & 0.60 & 0.87 \\
\hline
\end{tabular}

SGI group, group with slow growth during infancy; CON group, control group.

${ }^{*} P$ values reflect differences between the groups, tested by independent sample $t$ tests.

$\dagger \mathrm{BMI}$ at 1 year of age conditional on BMI at birth.

$\neq$ Fasting values are based on the first study visit.

$\S$ The $2 \mathrm{~h}$ glucose value is based on the oral glucose tolerance test.

hormones and the metabolites generated by dipeptidyl peptidase. The results therefore reflect the secretion of GLP-1.

\section{Statistical analysis}

GLP-1 and subjective satiety profiles were measured only in the whey meal and the casein meal. The $4 \mathrm{~h}$ incremental area under the glucose, insulin, TAG, PYY, GIP and GLP-1 response curve (incremental AUC) and the $4 \mathrm{~h}$ incremental area over the NEFA response curve (incremental area over the curve) were calculated using a trapezoidal method for each test meal ${ }^{(27)}$. In addition, the $2 \mathrm{~h}$ glucose, insulin PYY, GIP and GLP-1 incremental AUC and the $4 \mathrm{~h}$ total AUC of the satiety profile, and ghrelin were also calculated.

Glucose, insulin, TAG, PYY, ghrelin and GLP-1 responses were not normally distributed and were therefore log-transformed. Repeated-measures ANOVA was used for testing the differences between the study groups. If repeated-measures ANOVA was significant, an independent sample $t$ test was used to test whether the study groups differed from each other in the different test meals. An independent sample $t$ test was also used for testing the differences in the baseline characteristics of the subjects between the study groups. All statistical analyses were carried out with the PASW Statistics version 18 for Windows ${ }^{\circledR}$ (SPSS Inc.). The level of significance was $P<0 \cdot 05$. Results are expressed as means with their standard errors, except for the subjects' characteristics, which are presented as means and standard deviations.

\section{Results}

\section{Subject characteristics}

The baseline characteristics of the subjects are illustrated in Table 2. Although the subjects in the SGI group were slightly shorter and lighter in adulthood compared with the CON group, the mean BMI of the study groups was identical $\left(27 \cdot 0 \mathrm{~kg} / \mathrm{m}^{2}\right)$. In addition, no differences were observed between the study groups in fasting concentrations of glucose, insulin and lipids. Cholesterol-lowering medication (statins) was used in five subjects in the SGI group and four in the CON group. Moreover, seven subjects in the SGI group and five subjects in the CON group had impaired glucose tolerance ( $2 \mathrm{~h}$ glucose concentration $>7 \cdot 8 \mathrm{mmol} / \mathrm{l}$ ).

\section{Glucose and insulin responses}

After the ingestion of all test meals, the concentration of plasma glucose slightly increased during 15-30 min, declining thereafter and returning towards the fasting concentrations (Fig. 1). The 2 and $4 \mathrm{~h}$ glucose responses did not differ significantly between the study groups (Table 3 ).

Growth during infancy affected the insulin postprandial responses and the 2 and $4 \mathrm{~h}$ insulin responses were significantly higher for the SGI group compared with the CON group after the casein meal $(P=0.031$ and $P=0 \cdot 023$, respectively), the whey meal ( $P=0.066$ and $P=0.037$, respectively) 

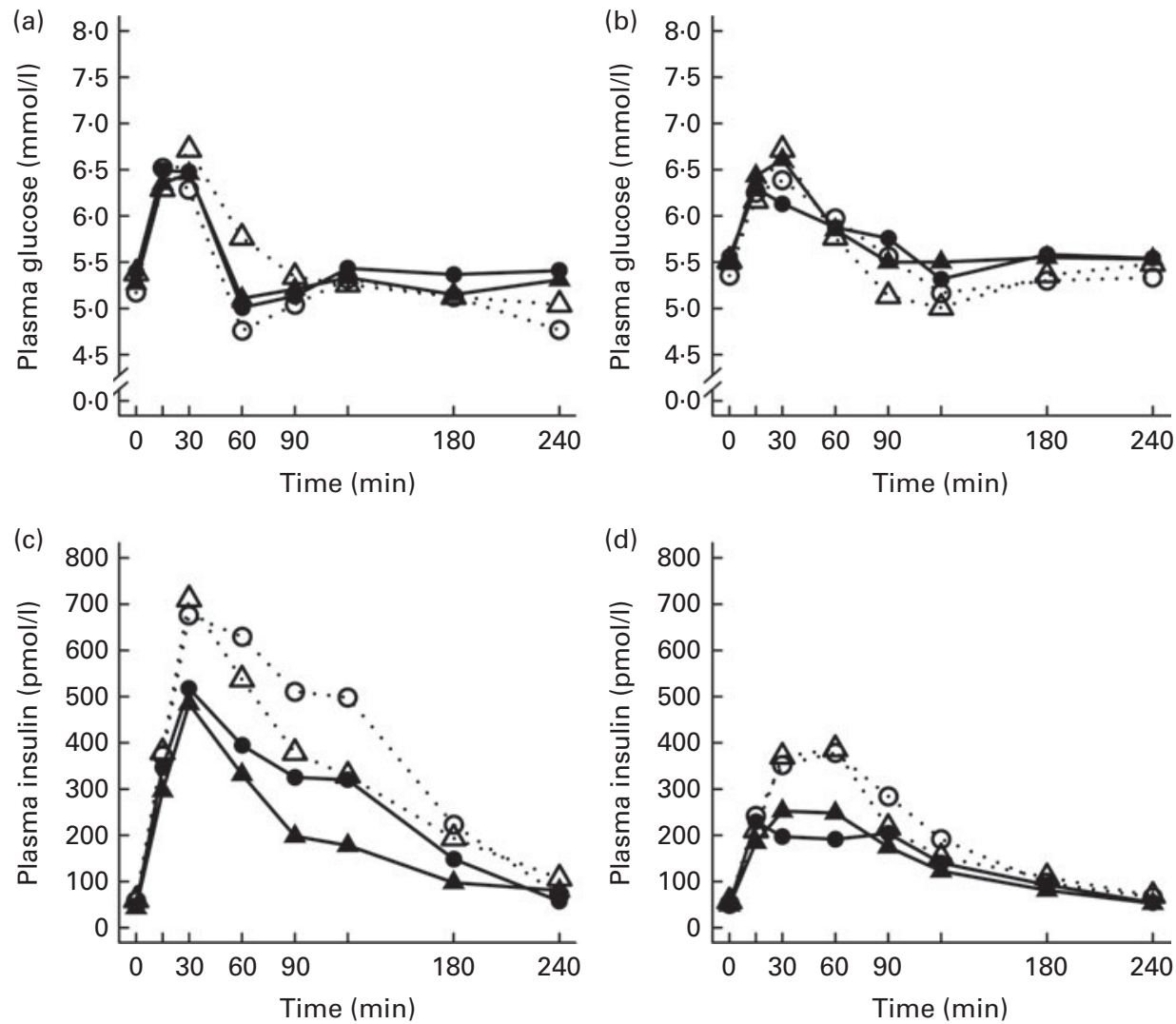

Fig. 1. Mean responses of plasma glucose to (a) a casein meal $(\Delta, \mathbf{\Delta})$ and whey meal $(\mathrm{O}, \bullet)$ and (b) a SFA meal $(\Delta, \mathbf{\Delta})$ and PUFA meal $(O, \bullet)$ and insulin to (c) a casein meal $(\Delta, \mathbf{\Lambda})$ and whey meal $(\mathrm{O}, \boldsymbol{\bullet})$ and $(\mathrm{d})$ a SFA meal $(\Delta, \mathbf{\Lambda})$ and PUFA meal $(\mathrm{O}, \boldsymbol{\bullet})$ for subjects with a small body size at birth and slow growth during infancy $(\mathrm{O}, \Delta)$ and for the control group $(\bullet, \mathbf{\Lambda})$.

and the PUFA meal ( $P=0.008$ and $P=0.002$, respectively) (Fig. 1; Table 3). The 2 and $4 \mathrm{~h}$ insulin responses were also greater for the SGI group compared with the controls after the SFA meal ( $P=0.073$ and $P=0.61$, respectively), although differences did not reach a statistically significant level.

\section{TAG and NEFA responses}

The $4 \mathrm{~h}$ TAG responses of the test meals were significantly higher for the SGI group compared with the CON group (Fig. 2; Table 3). Additional analyses showed that the postprandial response of the PUFA meal was higher for the SGI group $(P=0.006)$ and produced a 1.7 -fold higher TAG response compared with the controls. Postprandial TAG responses of the whey meal $(P=0.053)$, casein meal $(P=0.158)$ and SFA meal $(P=0.074)$ were also higher for the SGI group than the CON group; however, the differences did not reach a statistically significant level. NEFA responses did not differ significantly between the study groups (Table 3). All the study meals suppressed NEFA initially and reached the nadir within 60-90 min.

\section{Appetite regulatory hormone and incretin responses}

The postprandial concentration of PYY increased (Fig. 3) and ghrelin decreased (Fig. 2) after the consumption of the test meals. Postprandial PYY responses were slightly higher for the SGI group compared with the CON group in all the test meals (Table 3). However, only the $2 \mathrm{~h}$ responses differed significantly between the study groups after the whey meal $(P=0.046)$ and after the casein meal $(P=0 \cdot 025)$. The total ghrelin responses were slightly greater for the SGI group after two high-protein meals and slightly smaller after two high-fat meals; however, the differences did not reach a statistically significant level (Fig. 2; Table 3).

The measures of subjective satiety (visual analogue scale) increased after the ingestion of both high-protein meals, reaching peak values by $30-60 \mathrm{~min}$ and declining thereafter (Fig. 3). The total $4 \mathrm{~h}$ visual analogue scale response curve was slightly, but not significantly, higher for the SGI group after the whey meal (882 (SE 68) $v .781$ (SE 62); $P=0 \cdot 28)$ and after the casein meal (803 (SE 56) v. 777 (SE 57); $P=0.77$ ).

Neither fasting concentrations nor postprandial responses of GLP-1 or GIP differed significantly between the study groups (Table 3). Postprandial concentrations of GLP-1 peaked at $120 \mathrm{~min}$ and GIP at $90-120 \mathrm{~min}$ after the consumption of all the study meals, after which the concentrations declined towards the baseline values (Fig. 3).

\section{Discussion}

We investigated the influence of early growth on the postprandial responses of appetite regulatory hormones to two highprotein and two high-fat content meals in overweight adult men and women. We showed that postprandial responses of 
Table 3. Postprandial 2 and $4 \mathrm{~h}$ responses of the test meals

(Mean values with their standard errors)

\begin{tabular}{|c|c|c|c|c|c|c|c|c|c|c|c|c|c|c|c|c|c|}
\hline & \multicolumn{4}{|c|}{ Whey meal } & \multicolumn{4}{|c|}{ Casein meal } & \multicolumn{4}{|c|}{ PUFA meal } & \multicolumn{4}{|c|}{ SFA meal } & \multirow[b]{3}{*}{$P^{\star}$} \\
\hline & \multicolumn{2}{|c|}{ SGI group } & \multicolumn{2}{|c|}{ CON group } & \multicolumn{2}{|c|}{ SGI group } & \multicolumn{2}{|c|}{ CON group } & \multicolumn{2}{|c|}{ SGI group } & \multicolumn{2}{|c|}{ CON group } & \multicolumn{2}{|c|}{ SGI group } & \multicolumn{2}{|c|}{ CON group } & \\
\hline & Mean & SE & Mean & SE & Mean & SE & Mean & SE & Mean & SE & Mean & SE & Mean & SE & Mean & SE & \\
\hline $\begin{array}{l}2 \mathrm{~h} \text { Glucose IAUC } \\
(\mathrm{mmol} \times \mathrm{min} / \mathrm{l}) \ddagger\end{array}$ & 55 & 16 & 48 & 11 & 83 & 22 & 53 & 13 & 72 & 17 & 43 & 9 & 55 & 13 & 67 & 13 & 0.363 \\
\hline $\begin{array}{r}4 \mathrm{~h} \text { Glucose IAUC } \\
(\mathrm{mmol} \times \mathrm{min} / \mathrm{l}) \ddagger\end{array}$ & 88 & 23 & 81 & 14 & 105 & 24 & 81 & 19 & 103 & 16 & 77 & 12 & 80 & 20 & 103 & 24 & 0.963 \\
\hline $\begin{array}{l}2 \mathrm{~h} \text { Insulin IAUC } \\
(\mathrm{pmol} \times \mathrm{min} / \mathrm{l}) \ddagger\end{array}$ & 57524 & 9066 & 38115 & 8200 & $49192 \dagger$ & 6817 & 30366 & 5721 & $27869 \dagger$ & 5563 & 13508 & 1485 & 27083 & 3644 & 17314 & 2359 & 0.025 \\
\hline $\begin{array}{l}4 \mathrm{~h} \text { Insulin IAUC } \\
(\mathrm{pmol} \times \mathrm{min} / \mathrm{l}) \ddagger\end{array}$ & $81107 \dagger$ & 13418 & 52570 & 11881 & $66607 \dagger$ & 10168 & 38636 & 6946 & $35227 \dagger$ & 6885 & 19203 & 3203 & 33469 & 4824 & 21608 & 3150 & 0.036 \\
\hline $\begin{array}{l}\text { 4h TAG IAUC } \\
(\mathrm{mmol} \times \mathrm{min} / \mathrm{l}) \ddagger\end{array}$ & 70 & 11 & 45 & 10 & 59 & 9 & 44 & 8 & $154 \dagger$ & 21 & 91 & 10 & 132 & 18 & 88 & 12 & 0.015 \\
\hline $\begin{array}{l}\text { 4h hEFA IAOC } \\
(\mathrm{mmol} \times \mathrm{min} / \mathrm{l})\end{array}$ & 59 & 10 & 89 & 12 & 71 & 13 & 55 & 9 & 36 & 11 & 41 & 9 & 31 & 9 & 38 & 7 & 0.384 \\
\hline $\begin{array}{l}2 \mathrm{~h} \text { PYY IAUC } \\
(\mathrm{pg} \times \mathrm{min} / \mathrm{ml}) \ddagger\end{array}$ & $6880 \dagger$ & 830 & 4772 & 977 & $6876 \dagger$ & 1549 & 3196 & 994 & 7097 & 1222 & 8849 & 1682 & 6218 & 1428 & 3229 & 848 & 0.005 \\
\hline $\begin{array}{l}\text { 4h PYY IAUC } \\
(\mathrm{pg} \times \mathrm{min} / \mathrm{ml}) \ddagger\end{array}$ & 11010 & 1898 & 8042 & 1536 & 11300 & 2895 & 6151 & 1646 & 15955 & 3373 & 20944 & 4086 & 15537 & 5589 & 8393 & 1952 & $0 \cdot 15$ \\
\hline $\begin{array}{c}4 \mathrm{~h} \text { Ghrelin total AUC } \\
(\mathrm{pg} \times \mathrm{min} / \mathrm{ml}) \ddagger\end{array}$ & 5213 & 1033 & 4390 & 746 & 6410 & 1469 & 5081 & 1033 & 6156 & 1056 & 7347 & 576 & 6673 & 1104 & 7515 & 857 & 0.949 \\
\hline $\begin{array}{l}2 \mathrm{~h} \text { GIP IAUC } \\
(\mathrm{pg} \times \mathrm{min} / \mathrm{ml})\end{array}$ & 35222 & 4519 & 36445 & 7063 & 26990 & 3218 & 26818 & 4653 & 35848 & 6324 & 21034 & 5421 & 31376 & 4682 & 34776 & 9228 & 0.784 \\
\hline $\begin{array}{l}\text { 4h GIP IAUC } \\
(\mathrm{pg} \times \mathrm{min} / \mathrm{ml})\end{array}$ & 71880 & 7896 & 77132 & 12001 & 63734 & 6139 & 61819 & 9387 & 81344 & 13974 & 56530 & 11113 & 72576 & 9128 & 72323 & 14593 & 0.698 \\
\hline $\begin{array}{l}2 \mathrm{~h} \mathrm{GLP}-1 \text { IAUC } \\
(\mathrm{pmol} \times \mathrm{min} / \mathrm{l}) \ddagger\end{array}$ & 1810 & 400 & 2058 & 422 & 2283 & 925 & 1466 & 353 & \multicolumn{2}{|c|}{ NA } & \multicolumn{2}{|c|}{ NA } & \multicolumn{2}{|c|}{ NA } & \multicolumn{2}{|c|}{ NA } & 0.863 \\
\hline $\begin{array}{l}\text { 4h GLP-1 IAUC } \\
(\mathrm{pmol} \times \min / \mathrm{l}) \ddagger\end{array}$ & 3587 & 676 & 3765 & 671 & 4312 & 1369 & 2743 & 619 & \multicolumn{2}{|c|}{ NA } & \multicolumn{2}{|c|}{ NA } & $\mathrm{N}$ & & \multicolumn{2}{|c|}{ NA } & 0.294 \\
\hline
\end{tabular}

SGI group, slow growth during infancy; CON group, control group; IAUC, incremental AUC; IAOC, incremental area over the curve; PYY, peptide tyrosine-tyrosine; GIP, glucose-dependent insulinotropic peptide; GLP-1, glucagon-

like peptide-1; NA, not analysed.
"Differences between the groups tested by repeated-measures ANOVA. If significant $(P<0.05)$, an independent sample $t$ test was performed to test whether the study groups differed from each other in the different test meals. † Mean values were significantly different from the $\mathrm{CON}$ group $(P<0.05$; independent sample $t$ test).

Postprandial responses were log-transformed before the analyses. 

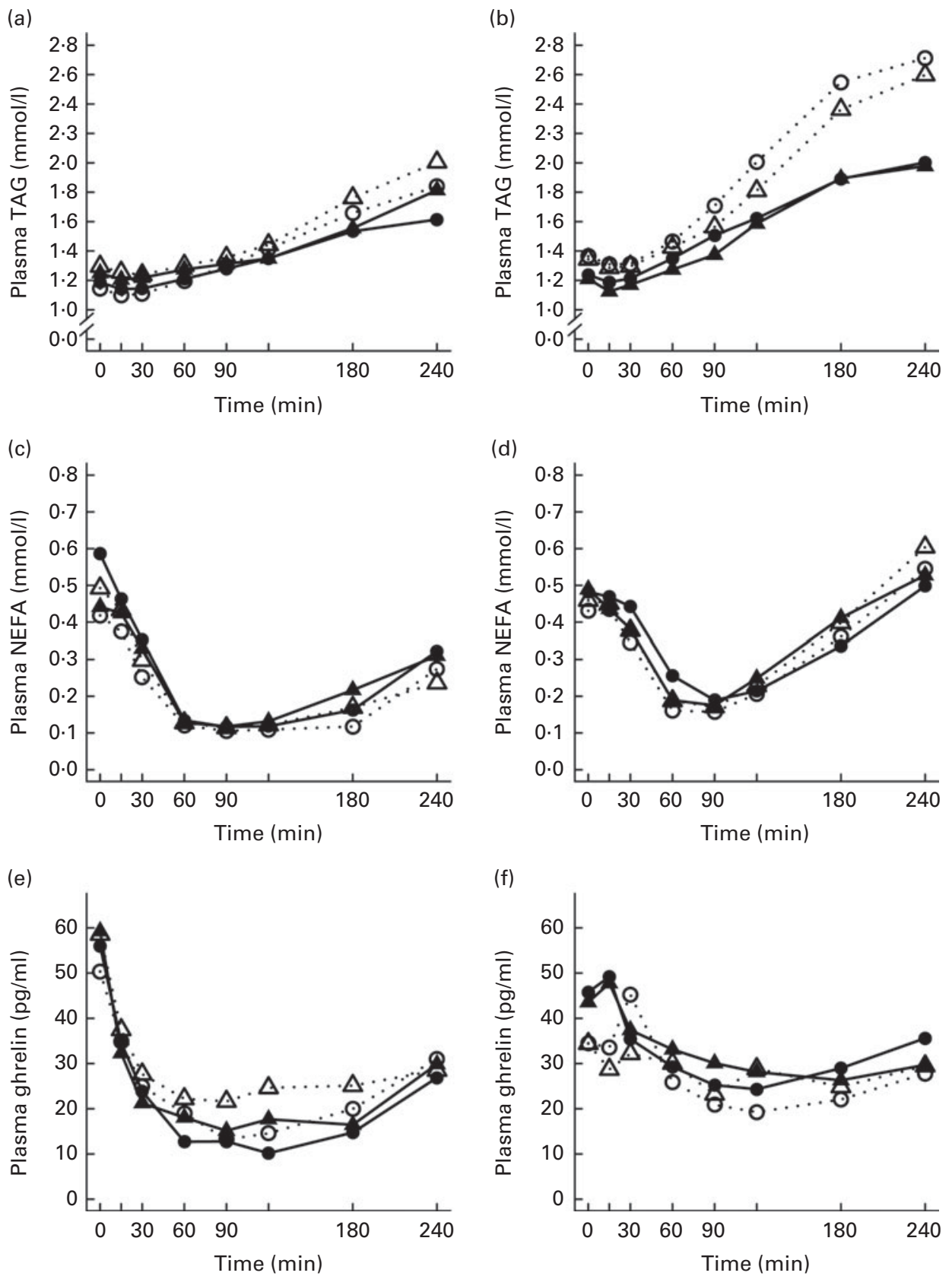

Fig. 2. Mean responses of plasma TAG to (a) a casein meal $(\Delta, \mathbf{\Delta})$ and whey meal $(\mathrm{O}, \bullet)$ and (b) a SFA meal $(\Delta, \mathbf{\Lambda})$ and PUFA meal $(\mathrm{O}, \bullet)$, NEFA to (c) a casein meal $(\Delta, \mathbf{\Lambda})$ and whey meal $(\mathrm{O}, \boldsymbol{\bullet})$ and $(\mathrm{d})$ a SFA meal $(\Delta, \boldsymbol{\Delta})$ and PUFA meal $(\mathrm{O}, \boldsymbol{\bullet})$ and ghrelin (e) a casein meal $(\Delta, \boldsymbol{\Delta})$ and whey meal $(\mathrm{O}, \boldsymbol{\bullet})$ and $(\mathrm{f})$ a SFA meal $(\Delta, \mathbf{\Lambda})$ and PUFA meal $(\mathrm{O}, \bullet)$ for subjects with a small body size at birth and slow growth during infancy $(\mathrm{O}, \Delta)$ and for the control group $(\bullet, \mathbf{\Delta})$.

the appetite regulatory hormone PYY were significantly higher and satiety profiles were slightly, but not significantly, greater for the SGI group. To our knowledge, this is the first study that has examined the effect of early growth on postprandial appetite regulatory hormone responses in adults. In addition, postprandial insulin and TAG responses were significantly higher for the SGI group compared with the age-, sex- and BMI-matched controls. Insulin responses were especially higher after the high-protein content meals and TAG responses after the high-fat content meals. We have previously reported that postprandial TAG and insulin responses of these same individuals after the high-carbohydrate and high-fat content fast-food meal were significantly higher for subjects with slow early growth compared with age- and BMI-matched controls, as well as slightly higher after a breakfast prepared according to nutritional recommendations ${ }^{(18)}$. In the present study, we showed that postprandial TAG responses were also higher after a high-protein meal that contained only a moderate amount of fat $(23 \mathrm{~g})$.

The present finding of increased anorexigenic PYY responses as well as a slightly greater subjective satiety profile may indicate greater satiety responses after the meal among subjects who grew slowly during early life. This result supports the hypothesis that early growth may programme 
(a)

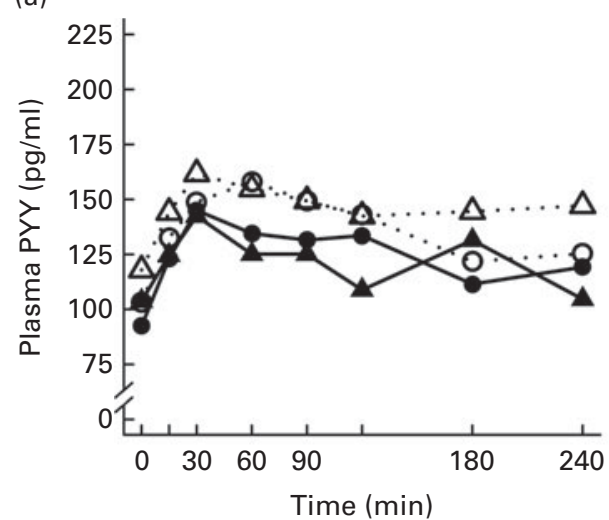

(c)

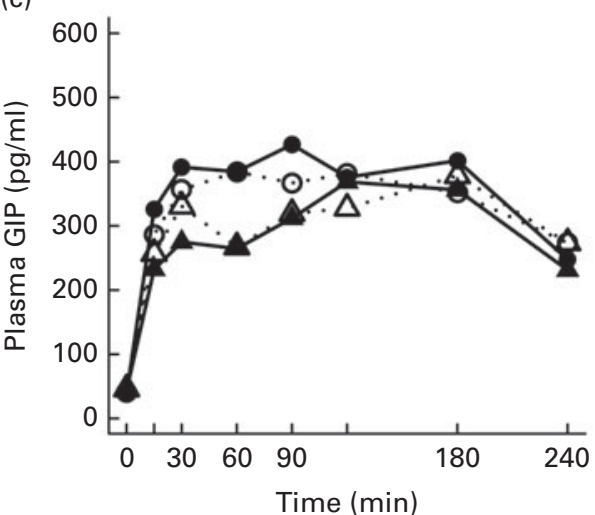

(e)

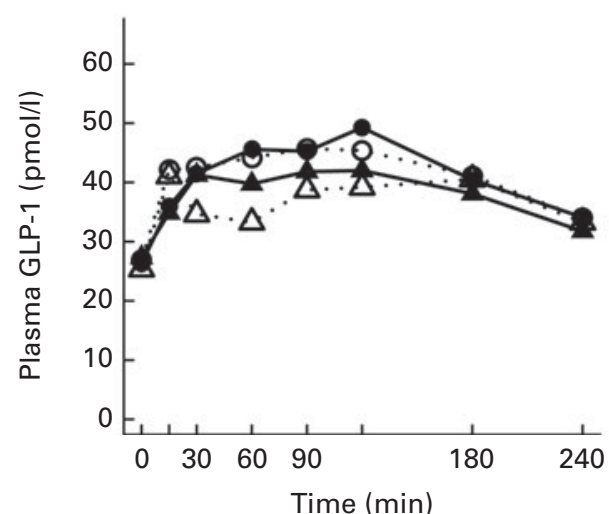

(b)

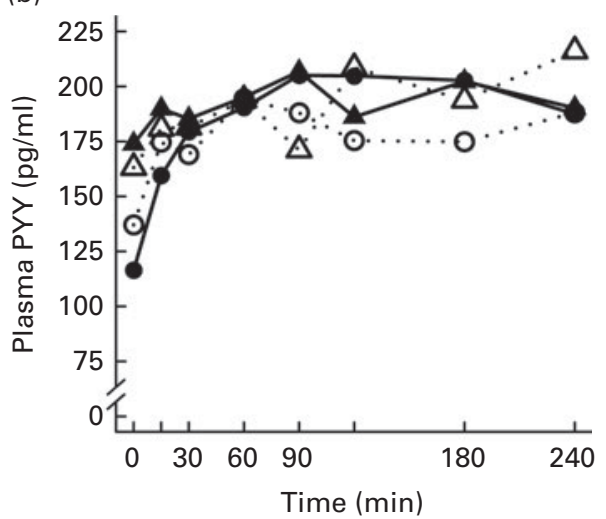

(d)

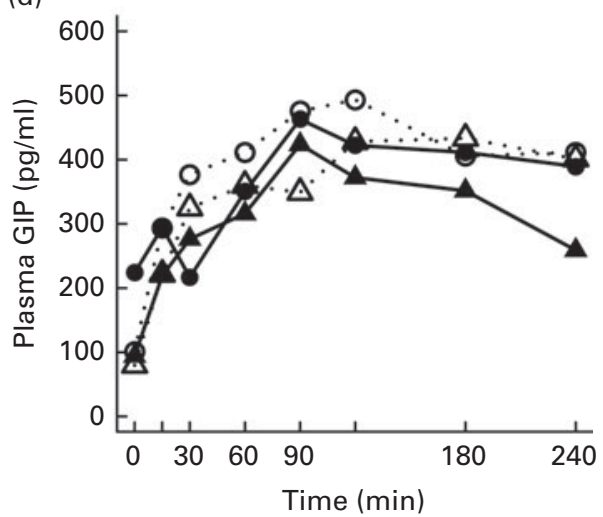

(f)

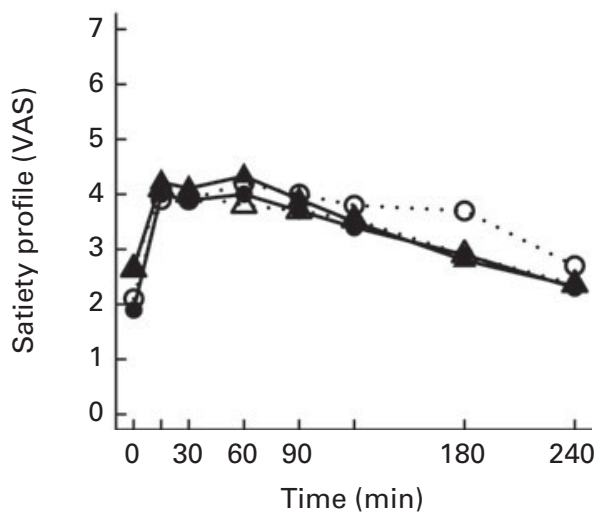

Fig. 3. Mean responses of plasma peptide tyrosine-tyrosine (PYY) to (a) a casein meal $(\Delta, \mathbf{\Lambda})$ and whey meal $(\mathrm{O}, \boldsymbol{\bullet})$ and $(\mathrm{b})$ a SFA meal $(\Delta, \mathbf{\Lambda})$ and PUFA meal $(\mathrm{O}, \bullet)$, glucose-dependent insulinotropic peptide (GIP) to (c) a casein meal $(\Delta, \mathbf{\Delta})$ and whey meal $(\mathrm{O}, \bullet)$ and $(\mathrm{d})$ a SFA meal $(\Delta, \mathbf{\Lambda})$ and PUFA meal $(\mathrm{O}, \bullet)$, glucagon-like peptide-1 (GLP-1) to (e) a casein meal $(\Delta, \mathbf{\Lambda})$ and whey meal $(\mathrm{O}, \boldsymbol{\bullet})$ and satiety profile (visual analogue scale; VAS) to (f) a casein meal $(\Delta, \mathbf{\Delta})$ and whey meal $(\mathrm{O}, \bullet)$ for subjects with a small body size at birth and slow growth during infancy $(\mathrm{O}, \Delta)$ and for the control group $(\bullet, \mathbf{\Lambda})$.

appetite regulatory systems. There is strong epidemiological evidence that subjects who were born with a small body size and grew slowly during infancy are less likely to become obese in adult life, whereas rapid growth during infancy has been associated with obesity in later life ${ }^{(3-6)}$. We suggest that this could be, at least partly, due to a programmed appetite regulatory system. An epidemiological study has supported this by showing that rapid weight gain in infancy is associated with a higher fasting concentration of ghrelin, reflecting alterations in the appetite regulatory system ${ }^{(12)}$.
The present results are also in accordance with previous studies of young children which showed that infants who were born with a low birth weight ${ }^{(13)}$ or born preterm ${ }^{(13,28,29)}$ had elevated levels of fasting PYY, reflecting greater satiety. The results from previous studies in which the association between birth weight and fasting levels of ghrelin has been investigated are conflicting, showing no differences ${ }^{(14,16)}$, decreased $^{(13)}$ or even elevated ${ }^{(15,17)}$ ghrelin levels among children born with a low birth weight compared with controls. To our knowledge, only one study has investigated the effect 
of birth weight on postprandial appetite regulatory hormone responses in adulthood, and detected no effect of birth weight ${ }^{(22)}$. However, in contrast to the present study, they measured only GLP-1 levels, not other hormones that are involved in appetite regulation. In addition to the incretin effect, GLP-1 also delays the transit of nutrients from the stomach to the duodenum and decreases food intake ${ }^{(30)}$. It has also been demonstrated in animal models that postnatal growth retardation has a greater effect on appetite regulation than prenatal growth ${ }^{(8)}$; however, contradictory results also exist ${ }^{(31)}$.

Our observations of elevated insulin responses among individuals who grew slowly during early life may illustrate insulin resistance. This finding is consistent with previous studies that have reported increased insulin responses and impaired insulin sensitivity among low-birth-weight participants after intravenous or oral glucose tolerance testing ${ }^{(32)}$. In addition, insulin is also an important satiety signal ${ }^{(33)}$. The observed elevated postprandial insulin responses in the SGI group may thus also reflect higher satiety feelings in the postprandial state. In spite of over 1.5-fold higher insulin responses in the SGI group, we did not find differences in GLP-1 and GIP responses between the study groups. This finding is in line with a previous study of Schou et al. ${ }^{(22)}$, who found that subjects with a low birth weight had higher insulin responses compared with matched normalbirth-weight participants, whereas GLP-1 and GIP responses did not differ between the groups. In addition, it has been demonstrated that GLP-1 concentrations after a meal are impaired in type 2 diabetics and only slightly reduced in participants with impaired glucose tolerance ${ }^{(21)}$. Therefore, it is likely that growth retardation during early life alone does not affect incretin levels.

Although fasting TAG concentrations did not differ significantly between the study groups, we observed higher postprandial TAG responses after the high-protein and high-fat content meals for the SGI group compared with the CON group. This finding indicates that individuals who grew slowly during early life may have changed lipid metabolism, which could be the result of altered liver function, as detected in animal studies ${ }^{(34-36)}$. It has been reported earlier that prenatal growth has only a moderate effect on fasting ${ }^{(37)}$ and postprandial $^{(38,39)}$ TAG levels, whereas postnatal growth has a much greater effect ${ }^{(18,23)}$. Therefore, we suggest that our observed elevated TAG responses are mostly due to growth retardation during infancy.

We have previously discussed the possible limitations of the present study ${ }^{(18)}$. Briefly, although the recruiting criteria of the present study groups were growth during the first year of life, the present study subjects who had grown slowly during the first year of life were also born with a small body size. Thus, we cannot distinguish between the effect of body size at birth, postnatal growth or the combination of the two on postprandial responses. In addition, as all subjects were 65-75 years old, the present findings of early growth and postprandial responses need to be confirmed also in younger populations. A possible limitation of the present study may also be the small sample size; therefore, further studies are needed to replicate the present findings. Moreover, the assay that we used for PYY determination did not differentiate between PYY (1-36) and PYY (3-36); therefore, total hormone concentrations may not reflect active hormone levels. The different form of PYY may also have different roles in food intake regulations ${ }^{(40)}$. Therefore, we cannot know whether the active PYY responses would have been different among the study groups.

In conclusion, the findings of the present study suggest a programming effect of early growth on the concentrations of PYY. The present results also indicate that slow early growth may have an adverse effect on postprandial insulin and TAG responses in adulthood. Different appetite regulatory hormone responses may at least partly explain the decreased risk of obesity in later adult life among individuals who experienced slow growth during early life.

\section{Acknowledgements}

We thank the volunteers for taking the time to participate in the postprandial study, Sigrid Rosten for assisting with the technical aspects of the study and Elina Rintala for assistance in blood sampling. The present study was supported by grants from the Academy of Finland, Finska Läkaresällskapet, Samfundet Folkhälsan, Liv och Hälsa, the Juho Vainio Foundation, the Novo Nordisk Foundation, the Päivikki and Sakari Sohlberg Foundation, the Signe and Ane Gyllenberg Foundation, the Yrjö Jahnsson Foundation, The Diabetes Research Foundation, the Finnish Foundation for Cardiovascular Research and the Finnish Graduate School on Applied Bioscience. The contribution of each author was as follows: M.-M. P. wrote the first draft of the manuscript, carried out the postprandial studies and performed the statistical analysis; M.-M. P., E. K., L. M. V. and J. G. E. contributed to the conception and design of the study; J. J. H. and J. L. were responsible for the analysis of the blood samples; M.-M. P., E. K. and J. G. E. participated in the writing of the final draft of the manuscript. All the authors contributed to the critical revision of the manuscript. The funding sources had no role in the study design, collection, analysis or interpretation of the data or writing of the report. None of the authors had a conflict of interest.

\section{References}

1. Huxley R, Owen CG, Whincup PH, et al. (2007) Is birth weight a risk factor for ischemic heart disease in later life? Am J Clin Nutr 85, 1244-1250.

2. Whincup PH, Kaye SJ, Owen CG, et al. (2008) Birth weight and risk of type 2 diabetes: a systematic review. JAMA 300, 2886-2897.

3. Baird J, Fisher D, Lucas P, et al. (2005) Being big or growing fast: systematic review of size and growth in infancy and later obesity. BMJ 331, 929.

4. Monteiro PO \& Victora CG (2005) Rapid growth in infancy and childhood and obesity in later life - a systematic review. Obes Rev 6, 143-154.

5. Monasta L, Batty GD, Cattaneo A, et al. (2010) Early-life determinants of overweight and obesity: a review of systematic reviews. Obes Rev 11, 695-708. 
6. Yu ZB, Han SP, Zhu GZ, et al. (2011) Birth weight and subsequent risk of obesity: a systematic review and metaanalysis. Obes Rev 12, 525-542.

7. Wang X, Liang L \& Du L (2007) The effects of intrauterine undernutrition on pancreas ghrelin and insulin expression in neonate rats. J Endocrinol 194, 121-129.

8. Yousheng J, Nguyen T, Desai M, et al. (2008) Programmed alterations in hypothalamic neuronal orexigenic responses to ghrelin following gestational nutrient restriction. Reprod Sci 15, 702-709.

9. Nagata E, Nakagawa Y, Yamaguchi R, et al. (2011) Altered gene expressions of ghrelin, PYY, and CCK in the gastrointestinal tract of the hyperphagic intrauterine growth restriction rat offspring. Horm Metab Res 43, 178-182.

10. Ozanne SE, Lewis R, Jennings BJ, et al. (2004) Early programming of weight gain in mice prevents the induction of obesity by a highly palatable diet. Clin Sci (Lond) 106, $141-145$

11. Desai M, Gayle D, Babu J, et al. (2005) Programmed obesity in intrauterine growth-restricted newborns: modulation by newborn nutrition. Am J Physiol Regul Integr Comp Physiol 288, R91-R96.

12. Larnkjær A, Schack-Nielsen L, Mølgaard C, et al. (2010) Effect of growth in infancy on body composition, insulin resistance, and concentration of appetite hormones in adolescence. Am J Clin Nutr 91, 1675-1683.

13. Siahanidou T, Mandyla H, Vounatsou M, et al. (2005) Circulating peptide YY concentrations are higher in preterm than full-term infants and correlate negatively with body weight and positively with serum ghrelin concentrations Clin Chem 51, 2131-2137.

14. Iñiguez $G$, Ong $K$, Peña $V$, et al. (2002) Fasting and post-glucose ghrelin levels in SGA infants: relationships with size and weight gain at one year of age. J Clin Endocrinol Metab 87, 5830-5833.

15. Darendeliler F, Poyrazoglu S, Bas F, et al. (2009) Ghrelin levels are decreased in non-obese prepubertal children born large for gestational age. Eur J Endocrinol 160, 951-956.

16. Kyriakakou M, Malamitsi-Puchner A, Mastorakos G, et al (2009) The role of IGF-1 and ghrelin in the compensation of intrauterine growth restriction. Reprod Sci 16, 1193-1200.

17. Park E (2010) Birth weight was negatively correlated with plasma ghrelin, insulin resistance, and coenzyme Q10 levels in overweight children. Nutr Res Pract 4, 311-316.

18. Perälä MM, Valsta LM, Kajantie E, et al. (2011) Impact of early growth on postprandial responses in later life. PLoS One $\mathbf{6}$, e24070.

19. Perälä MM \& Eriksson JG (2012) Early growth and postprandial glucose, insulin, lipid and inflammatory responses in adulthood. Curr Opin Lipidol 23, 327-333.

20. Kazakos K (2011) Incretin effect: GLP-1, GIP, DPP4. Diabet Res Clin Pract 93, S32-S36.

21. Nauck MA, Vardarli I, Deacon CF, et al. (2011) Secretion of glucagon-like peptide-1 (GLP-1) in type 2 diabetes: what is up, what is down? Diabetologia 54, 10-18.

22. Schou JH, Pilgaard K, Vilsbøll T, et al. (2005) Normal secretion and action of the gut incretin hormones glucagon-like peptide-1 and glucose-dependent insulinotropic polypeptide in young men with low birth weight. J Clin Endocrinol Metab 90, 4912-4919.

23. Kajantie E, Barker DJ, Osmond C, et al. (2008) Growth before 2 years of age and serum lipids 60 years later: the Helsinki Birth Cohort study. Int J Epidemiol 37, 280-289.

24. FAO/WHO/UNU Expert Consultation (2004) Human energy requirements. Report of a joint $\mathrm{FAO} / \mathrm{WHO} / \mathrm{UNU}$ Expert
Consultation, Rome, 17-24 October 2001. In FAO Food and Nutrition Technical Report Series. Rome: WHO.

25. Holt SH \& Miller JB (1995) Increased insulin responses to ingested foods are associated with lessened satiety. Appetite 24, 43-54.

26. Orskov C, Rabenhoj L, Wettergren A, et al. (1994) Tissue and plasma concentrations of amidated and glycine-extended glucagon-like peptide I in humans. Diabetes 43, 535-539.

27. FAO/WHO Expert Consultation (1998) Carbohydrates in human nutrition. Report of a joint FAO/WHO Expert Consultation, Rome, 14-18 April, 1997. In FAO Food and Nutrition Papers. Rome: WHO.

28. Berseth CL, Nordyke CK, Valdes MG, et al. (1992) Responses of gastrointestinal peptides and motor activity to milk and water feedings in preterm and term infants. Pediatr Res 31, 587-590.

29. Siahanidou T, Mandyla H, Militsi H, et al. (2007) Peptide YY (3-36) represents a high percentage of total PYY immunoreactivity in preterm and full-term infants and correlates independently with markers of adiposity and serum ghrelin concentrations. Pediatr Res 62, 200-203.

30. Edholm T, Degerblad M, Gryback P, et al. (2010) Differential incretin effects of GIP and GLP-1 on gastric emptying, appetite, and insulin-glucose homeostasis. Neurogastroenterol Motil 22, 1191-1200, e1315.

31. Coupé B, Grit I, Darmaun D, et al. (2009) The timing of "catch-up growth" affects metabolism and appetite regulation in male rats born with intrauterine growth restriction. Am J Physiol Regul Integr Comp Physiol 297, R813-R824.

32. Newsome CA, Shiell AW, Fall CH, et al. (2003) Is birth weight related to later glucose and insulin metabolism? A systematic review. Diabet Med 20, 339-348.

33. Flint A, Gregersen NT, Gluud LL, et al. (2007) Associations between postprandial insulin and blood glucose responses, appetite sensations and energy intake in normal weight and overweight individuals: a meta-analysis of test meal studies. Br J Nutr 98, 17-25.

34. Winick M \& Noble A (1966) Cellular response in rats during malnutrition at various ages. J Nutr 89, 300-306.

35. Burns SP, Desai M, Cohen RD, et al. (1997) Gluconeogenesis, glucose handling, and structural changes in livers of the adult offspring of rats partially deprived of protein during pregnancy and lactation. J Clin Invest 100, 1768-1774.

36. Lane RH, Kelley DE, Gruetzmacher EM, et al. (2001) Uteroplacental insufficiency alters hepatic fatty acid-metabolizing enzymes in juvenile and adult rats. Am J Physiol Regul Integr Comp Physiol 280, R183-R190.

37. Huxley R, Owen CG, Whincup PH, et al. (2004) Birth weight and subsequent cholesterol levels: exploration of the "fetal origins" hypothesis. JAMA 292, 2755-2764.

38. Byrne CD, Wareham NJ, Phillips DI, et al. (1997) Is an exaggerated postprandial triglyceride response associated with the component features of the insulin resistance syndrome? Diabet Med 14, 942-950.

39. Kensara OA, Wooton SA, Phillips DI, et al. (2006) Substrate-energy metabolism and metabolic risk factors for cardiovascular disease in relation to fetal growth and adult body composition. Am J Physiol Endocrinol Metab 291, E365-E371.

40. Sloth B, Davidsen L, Holst JJ, et al. (2007) Effect of subcutaneous injections of PYY1-36 and PYY3-36 on appetite, ad libitum energy intake, and plasma free fatty acid concentration in obese males. Am J Physiol Endocrinol Metab 293, E604-E609. 